\title{
Sport and Healthy Competition
}

ISSN: 2577-1914

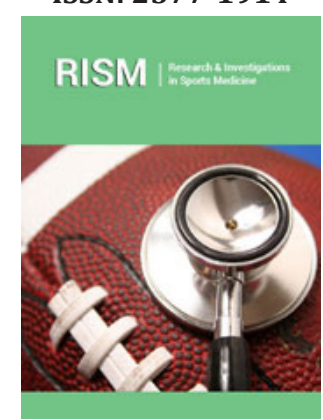

*Corresponding author: Mark Brooke, Senior Lecturer, National University of Singapore, Singapore

Submission:

Published: 侮 November 20, 2019

Volume 5 - Issue 4

How to cite this article: Mark Brooke. Sport and Health. Res Inves Sports Med. 5(4). RISM.000620.2019.

DOI: 10.31031/RISM.2019.05.000620

Copyright@ Mark Brooke, This article is distributed under the terms of the Creative Commons Attribution 4.0 International License, which permits unrestricted use and redistribution provided that the original author and source are credited.

\author{
Mark Brooke* \\ Senior Lecturer, National University of Singapore, Singapore
}

\section{Introduction}

Does sport provide positive health? The narrative has been debated for several decades. For example. moral values such as cooperative spirit as well as mental toughness are said to be learned qualities from sport participation [1]. However, it seems that other learning points might be aggression, violence and a win-at-all cost mentality [2]. This latter viewed clearly in the phenomenon of doping and deviant behaviour such as diving in football. So, is sport both a positive and negative stimulant? To what extent is health affected through sport participation?

\section{Positive Health Development}

Hamilton, et al. [3] argue that sport can be important as it enables:

'Individuals to lead a healthy, satisfying, and productive life, as youth and later as adults, because they gain the competence to earn a living, to engage in civic activities, to nurture others, and to participate in social relations and cultural activities'.

Positive health through the 5Cs. These 5Cs are competence, confidence, character, caring and connection. Competence is the ability to act correctly in a given context; confidence is valuing oneself; character is related to the respect of others; and caring is demonstrating compassion towards others. For example, Holt et al. [4] concluded that a group of children (average age 12) developed 'emotional control, exploration, confidence, discipline and academic performance' through sport participation. Moreover, it has been found that inclusivity can be learned through ice hockey [5]. Other health developments through sport participation have been reported to be self-esteem, competence, coping and resilience sportspersonship and fair play [1], and a shift away from a sedentary to a more active lifestyle.

\section{Negative Health Development}

On the other side of the coin, sport participation has been linked to anti-social behaviour. It is as George Orwell once said sport might be viewed as "war minus the shooting." Contact sports rely on aggressivity and have been linked to 'homophobia, sexism, racism, and ruthless competition' [6]. According to Kohn [7], the zero-sum outcome means that we need "to feel better by having the next person feel worse". He continues: "The struggle to defeat each other turns all of us into losers. Rather than building character, competition sabotages self-esteem and ruins relationships." In an environment where competition is fostered in this way, so too is selfishness developed through product-orientation. Kohn sees these characteristics of competitive sport as unhealthy for individuals and for society overall. Sport participation has been mixed up with the performance enhancing drug culture for several decades now [8], as it is with alcohol abuse, dating aggression [8] and extreme perfectionism as well as criticality towards others' acts [9], diminishing moral reasoning, and eating disorder amongst male and female athletes. In sum, there appears to be a substantial amount of literature to negate the sport for health narrative.

\section{Ways Forward}

With the ambiguity in the research, a new more inclusive sports practice might occur in schools particularly in the younger years [3-14]. First, youth require exposure to a range of activities. Early diversification rather than specialization is crucial. Deliberate play rather than deliberate practice activities should be encouraged. Social play helps to foster positive motor, 
cognitive and social learning. Healthy, not unhealthy competition and aggression should therefore be promoted. This would seem to be more aligned to the origins of competition itself. From an etymological perspective, competition means to strive with, and is not supposed to have evolved as to strive against.

Kohn [6] suggests cooperative sports with a much less significant focus on the zero-sum outcome. He argues for "new ways of participating in ball games during which competition is eliminated are encouraged and these emphasize participation, success, action, safety, fun, re-creation, friendship, challenge, diversity, player driven, in the moment, no competition." What the author calls "The 12 Key Elements of "True Play." Similarly, Constantinou [10] suggests that to enable the realization of healthy competition, youth should be introduced to activities from other cultures that more readily reproduce the characteristics of healthy competition such as Korfball and Tchoukball. Both sports are noncontact and mixed gendered. Thinking about the type of sport played by youth can promote social interaction and cooperation at the same time as providing vigorous physical activity. Other sports might be touch rugby and Ultimate Frisbee. However, knowing that other sports also have a strong tradition in the United States, Constantinou [10] also suggests including three simple rules in the playing of other competitive sports. Constantinou [10] rules are: First, keeping an arm's length away when engaging with one another should reduce aggression and provide more time for decision making and strategizing; second, teams are required to have carried out a minimum number of passes before attempting to shoot, guaranteeing that all players receive a pass to reduce any hogging of the play; and third, every team member must score before a player attempts to score a second time. These rules would drive players to devise team strategies by utilizing every member's strength. Moreover, team play and not the few elite players would dominate. These simple rules could be revolutionary if they were to be implemented as a generalized policy for school sports participation.

An organisation with strong roots in healthy competition and youth development through sport, which is growing in popularity in the United States, is i9 SPORTS (https://www.i9sports.com/) with a subscription of 2 million. They provide practice and coaching of popular sports such as flag football, soccer, basketball, baseball and Lacrosse. They recognise that inclusivity is paramount in youth sport as evidenced on their webpage:

In our programs, no child will ever be excluded by a try-out, be made to feel like they aren't good enough by a league draft, ride the bench for an entire game, or be cut from a team.

They go on to state that 'how you play a game is as important as the score. We don't just help kids become better athletes; we help them become better people'. They also strongly enforce a policy "When in Doubt Sit Out" to seek to ensure a sound Concussion Safety Policy. I think it is fair to say that this goes a little against the grain of what we know of sport in our societies, but it might become increasingly popular as its rewards are experienced by children and parents alike.

According to Hyman [11], in the United States alone, approximately 41 million youths engage in organized team sports, and parents might not be aware of the real impact that this might have. With the research into health development through sport, it is not a given that positive mental and physical health benefits are drawn from participation. What is needed is a conscious shift away from the value that militaristic sport is given, especially with regard to youth participation. Models such as the i9 experience seem to demonstrate that as parents do become more involved, they seek out genres of sport participation that stress health, or more importantly seek to do away with unhealthy competition.

\section{References}

1. Shields DLL, Bredemeier BJL (1995) Character development and physical activity. Human Kinetics Publishers, Champaign, Illinois, USA.

2. Coakley J (2011) Youth sports: What counts as positive development? Journal of sport and social issues 35(3): 306-324.

3. Hamilton SF, Hamilton MA, Pittman K (2004) Principles for youth development. The youth development handbook: Coming of age in American communities 2: 3-22.

4. Holt NL, Kingsley BC, Tink LN, Scherer J (2011) Benefits and challenges associated with sport participation by children and parents from lowincome families. Psychology of sport and exercise 12(5): 490-499.

5. Theberge N (2000) Higher goals: Women's ice hockey and the politics of gender. SUNY Press, New York, USA.

6. Kreager DA (2007) Unnecessary roughness? School sports, peer networks, and male adolescent violence. American sociological review 72(5): 705-724.

7. Kohn A (1986) No contest: The case against competition. Houghton Mifflin, Boston, USA.

8. Dodge TL, Jaccard JJ (2006) The effect of high school sports participation on the use of performance-enhancing substances in young adulthood. J Adolesc Health 39(3): 367-373.

9. Forbes GB, Adams-Curtis LE, Pakalka AH, White KB (2006) Dating aggression, sexual coercion, and aggression-supporting attitudes among college men as a function of participation in aggressive high school sports. Violence against Women 12(5): 441-455.

10. Hill AP, Witcher CSG, Gotwals JK, Leyland AF (2015) A qualitative study of perfectionism among self-identified perfectionists in sport and the performing arts. Sport, Exercise, and Performance Psychology 4(4): 237-253.

11. Constantinou P (2014) Promoting healthy competition using modified rules and sports from other cultures. Strategies 17(4): 29-33.

12. Hyman M (2009) Until it hurts: America's obsession with youth sports and how it harms our kids. Beacon Press, i9 Sports, Boston, USA.

13. Fraser-Thomas J, Cote J, Deakin J (2008) Understanding dropout and prolonged engagement in adolescent competitive sport. Psychology of Sport and Exercise 9(5): 645-662.

14. Taub DE, Blinde EM (1992) Eating disorders among adolescent female athletes: Influence of athletic participation and sport team membership. Adolescence 27(108): 833.

For possible submissions Click below: 